\title{
Necessidades térmicas de videiras na região da Campanha do Rio Grande do Sul - Brasil
}

\author{
Thermal requirement of vines in the Rio Grande do Sul region Campaign - Brazil
}

\author{
André Luiz Radünz ${ }^{I}$ Edgar Ricardo Schöffel ${ }^{\text {II }}$ Carolina Terra Borges ${ }^{\text {III }}$ \\ Marcelo Barbosa Malgarim ${ }^{\text {II }}$ Gabriela Hermann Pötter ${ }^{\text {IV }}$
}

\section{RESUMO}

A vitivinicultura, reconhecida por sua importância econômica e social no Rio Grande do Sul, tem ampliado sua fronteira de produção para a região da Campanha. Objetivouse com o presente trabalho avaliar o comportamento fenológico, bem como a necessidade térmica em graus-dia e a necessidade em dias, de cultivares de uvas finas destinadas à produção de vinhos, quando cultivadas na região da Campanha, local de recente introdução da espécie com caráter econômico. Os dados utilizados foram coletados em um vinhedo comercial, localizado no municipio de Dom Pedrito - RS, Brasil, durante as safras de 2007/2008, 2008/2009, 2009/2010, 2010/2011 e 2011/2012. Foram utilizadas as cultivares, 'Cabernet Sauvignon', 'Tannat', 'Tempranillo', 'Merlot', 'Gewurztraminer', 'Sauvignon Blanc'e 'Chardonnay'. Os resultados demonstram que as cultivares respondem de forma diferente quanto à necessidade térmica, em Graus-dia (GD), e à necessidade em dias para completar o ciclo, necessitando, em média, respectivamente, 2084 GD e 174 dias para a 'Cabernet Sauvignon', 1937 GD e 166 dias para 'Tempranillo', 1893 GD e 161dias para a 'Merlot', 1793 GD e 156 dias para 'Tannat', 1759 GD e 147 dias para a 'Sauvignon Blanc', 1689 GD e 152 dias para a 'Chardonnay' 1606 GD e 145 dias para a 'Gewurztraminer'. A maior necessidade térmica é na fase de desenvolvimento do fruto e maturação do fruto e a menor necessidade, na fase de floração.

Palavras-chave: fenologia, graus-dia, soma térmica, videiras, uvas viniferas.

\section{ABSTRACT}

The vitiviniculture, recognized for its economic and social importance in Rio Grande do Sul, has increased its production in the frontier of campaign region. The present study aimed to evaluate the phenological behavior, as well as the need for thermal degree-days and the need in days of cultivars of fine grapes intended for production wine, when cultivated in the campaign, local recent in the introduction of this species of economic nature. Data were collected in a commercial vineyard located in Dom Pedrito - RS, Brazil, during the growing seasons of 2007/2008, 2008/2009, 2009/2010, 2010/11 and 2011/12. The species cultivated were, 'Cabernet Sauvignon', 'Tannat', 'Tempranillo', 'Merlot', 'Gewurztraminer', 'Sauvignon Blanc'and 'Chardonnay'. The results demonstrated that cultivars responds differently to the need for thermal days to complete the cycle, requiring on average 2084 and 174 respectively for Cabernet Sauvignon, 1937 and 166 for 'Tempranillo', 161 and 1893 to 'Merlot', and 156 to 1793 for 'Tannat', and 147 to 1759 for 'Sauvignon Blanc', and 152 to 1689 for 'Chardonnay' and 145 to 1606 for 'Gewurztraminer'. The greatest need regarding thermal necessities is to fruit development and ripening and less need to flowering stage.

Key words: phenology; degree days; thermal demand; vines; wine grapes.

\section{INTRODUÇÃO}

A vitivinicultura, reconhecida no Rio Grande do Sul por sua importância econômica e social, tem, nos últimos anos, ampliado sua fronteira de produção para a região da Campanha, a qual tem demonstrado potenciais produtivos até então não explorados para produção de uvas.

A expansão do cultivo de videiras, para regiões não tradicionais, expõem as plantas a condições climáticas diferentes das conhecidas para a cultura, podendo provocar alterações fenológicas. Isto porque as videiras mudam o comportamento

\footnotetext{
'Programa de Pós-graduação em Agronomia (PPGA), Universidade Federal de Pelotas (UFPel), 96010-610, Pelotas, RS, Brasil. E-mail: alradunz@yahoo.com.br. Autor para correspondência.

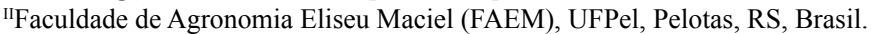

IIIPrograma de Pós-graduação em Ciência e Tecnologia de Sementes, UFPel, Pelotas, RS, Brasil.

${ }^{\text {IV }}$ Responsável técnica da Estância Guatambu, Dom Pedrito, RS, Brasil.
} 
fenológico e o acúmulo térmico necessário para completar o ciclo, quando cultivadas sob locais com condições micrometeorológicas distintas (FERREIRA et al., 2004; NEIS et al., 2010), podendo interferir positiva ou negativamente no crescimento e no desenvolvimento das plantas e, ainda, sob as características produtivas e qualitativas dos frutos (SILVA et al., 2009).

Diante do exposto, compreender a fenologia da videira, nos diferentes locais de cultivo, é importante para determinar a capacidade produtiva de uma região, para uma cultura, levando em conta o regime climático da região (MORLAT\& BODIN, 2006; WEBB et al., 2007). Logo, estudos que estabeleçam o índice térmico, em graus-dia, para a vitivinicultura em diferentes locais são imprescindíveis, uma vez que pesquisas demonstram variação na necessidade térmica e no número de dias para completar o ciclo para uma mesma cultivar (NEIS et al., 2010).

Para o vitivinicultor, a importância em conhecer a fenologia e as necessidades térmicas das cultivares está na possibilidade de este estimar as datas das fases fenológicas, auxiliando-o na tomada de decisão acerca do momento mais adequado de realizar os tratos culturais, bem como, programar as prováveis datas de colheita dos cachos, além de contribuir para o uso racional de agrotóxicos utilizados nos tratamentos fitossanitários e na otimização da mão de obra (RADÜNZ et al., 2012).

A caracterização das necessidades térmicas da videira mediante o conceito de graus-dia (GD) tem sido utilizada por muitos autores (FERREIRA et al., 2004; RUFFO ROBERTO et al., 2005; BRIXNER et al., 2010; NEIS et al., 2010; BRIGHENTI et al., 2013), sendo considerado um método eficiente para prever antecipadamente a data de colheita, mas também uma ferramenta simples e confiável para ser utilizada pelo vitivinicultor, pois considera apenas dados de temperatura.

Nesse contexto, tendo em vista a recente inserção da produção de uvas finas na região da Campanha, tornam-se necessários estudos que avaliem o desenvolvimento vegetal em função das condições climáticas. Assim, monitorando o ciclo de produção de um pomar comercial na região da Campanha, região sul do Rio Grande do Sul, o presente trabalho objetivou identificar o comportamento fenológico e quantificar a necessidade térmica de cultivares de uvas finas cultivadas na região da Campanha do Rio Grande do Sul.

\section{MATERIAL E MÉTODOS}

Os dados utilizados foram coletados pela equipe técnica da fazenda Guatambu, em um vinhedo comercial, localizado no município de Dom Pedrito - RS, Brasil (3058' S e 54²9' W,260m de altitude). As cultivares utilizadas foram a 'Cabernet
Sauvignon', 'Chardonnay' e 'Gewurztraminer', enxertadas sobre o porta-enxerto $\mathrm{SO}_{4}$, e as cultivares 'Tannat', 'Tempranillo', 'Merlot' e 'Sauvignon Blanc', que tinham como porta-enxerto o Paulsen 1103. Todas as cultivares foram conduzidas sob o sistema de espaldeira, com espaçamento de 2 metros entre plantas e de 3 metros entre fileiras, manejadas em cordão esporonado.

$\mathrm{O}$ delineamento experimento adotado foi inteiramente casualizado, conduzido sob esquema fatorial $5 \times 7$ (safra $\times$ cultivar), totalizando 35 tratamentos, com 5 repetições. Cada unidade experimental foi composta por uma planta, que foi avaliada durante todas as safras.

Os acompanhamentos fenológicos foram realizados semanalmente, através de avaliações visuais, durante cinco safras, 2007/2008, 2008/2009, 2009/2010, 2010/2011 e 2011/2012, sendo apresentados dados da necessidade térmica (Graus-dia, GD) e a necessidade em dias para o período brotação - colheita. Ainda, para as safras 2010/2011 e 2011/2012, são também apresentados dados detalhados referentes a seis fases fenológicas, segundo a escala BBCH ampliada (MONTEIRO et al., 2009): Desenvolvimento das Folhas (ponta verde até 5, 6 ou mais folhas); Aparecimento das inflorescências (inflorescências visíveis até inflorescência inteiramente desenvolvida); Floração (início floração até fim da floração); Desenvolvimento do fruto (início da formação do fruto até fim do fechamento do cacho); e Maturação (início da maturação até a colheita dos cachos). A colheita dos frutos foi determinada por refratometria, com auxílio de um refratômetro de campo, através de amostragens de frutos, realizadas a cada dois dias, durante a fase de maturação, em dez plantas, até estabilização no teor de sólidos solúveis.

Os dados de temperatura mínima e máxima foram coletados por uma estação meteorológica automática localizada na propriedade, sendo o cálculo do acúmulo térmico diário determinado através do método de graus-dia, equação:

$G D=\left(\frac{T \text { máx }-T \text { mín }}{2}\right)+(T \min -T b)$

em que: GD é Graus-dia; Tmáx é a temperatura máxima do dia; Tmín é a temperatura mínima do dia; Tb é a temperatura base da cultura, no caso $10^{\circ} \mathrm{C}$, considerada para todo o ciclo vegetativo (SATO et al., 2011; SANTOS etal., 2007; RUFFO ROBERTO etal., 2005).

Os dados de acúmulo térmico (GD) e necessidade em dias, referentes ao acompanhamento fenológicodoperíodopoda-colheita, foramsubmetidos à análise de variância e, quandoverificada significância, foram avaliados pelo teste de Tukey $(\mathrm{p} \leq 0,05)$. 


\section{RESULTADOS E DISCUSSÃO}

Os resultados em dias para completar o ciclo (Tabela 1) demonstram necessidades diferentes entre as cultivares analisadas, sendo a mais precoce a 'Gewurztraminer', em média 145 dias e a mais tardia a 'Cabernet Sauvignon', em média, 174 dias. A partir dos resultados, pode-se constatar que, para uma mesma cultivar, entre as safras avaliadas (Tabela 1), diferentes número de dias são requeridos para completar o ciclo, sendo, de maneira geral, maior a necessidade para a safra 2009/2010. A maior necessidade na safra 2009/2010 possivelmente esteja relacionada a temperaturas mais amenas durante esta safra (Figura 1D), convergindo para menor acúmulo térmico diário, que, por conseguinte, foi responsável por um ciclo mais longo em dias. Entretanto, cabe considerar que as maiores diferenças, em dias, entre as cinco safras analisadas, foram de apenas 24 para a 'Merlot', 20 para a 'Sauvignon Blanc', 12 para 'Tannat', 11 para a 'Cabernet Sauvignon' e 'Tempranillo',10 dias para a 'Chardonnay' e 8 dias para a 'Gewurztraminer'.

Essa variação em dias para completar o ciclo, entre as cultivares avaliadas, pode ser atribuída às características intrínsecas de cada cultivar, decorrentes da sua origem, e as condições meteorológicas, especialmente térmicas, sobre as quais as plantas estão expostas durante o ciclo produtivo (LEÃO\& SILVA, 2003; BRIXNER et al., 2010).

Considerando o número médio de dias para completar o ciclo, as cultivares 'Cabernet sauvignon' (174 dias), 'Sauvignon Blanc' (147 dias) e 'Merlot' (160 dias) foram, em média, 18\% inferiores às necessidades verificadas em São Joaquim, SC, por BORGHEZAN et al. (2011) que, ao avaliarem as cultivares 'Cabernet sauvignon', 'Sauvignon Blanc' e 'Merlot', constataram a necessidade de 210, 174 e 200 dias, respectivamente. Possivelmente, a menor necessidade em dias para completar o ciclo em São Joaquim, $\mathrm{SC}$, esteja relacionada às temperaturas mais baixas do munícipio, em relação à região da Campanha, RS. Valores próximos aos verificados neste trabalho foram relatados por LEEUWEN et al. (2004), em Bordeaux, com ciclo de aproximadamente 175 dias para as variedades 'Merlot' e 'Cabernet Sauvignon'.

Quanto à necessidade térmica, em grausdia (Tabela 1), os resultados demonstram existir diferenças entre as cultivares, sendo a 'Cabernet Sauvignon' superior às demais, com necessidade média de 2084 GD. Já o menor acúmulo térmico foi verificado para a cultivar 'Gewurztraminer' (Tabela 1), sendo, em média, 22,9\% menor que a 'Cabernet Sauvignon'. As maiores diferenças quanto ao requerimento térmico entre as cinco safras analisadas foram de $78 \mathrm{GD}$, 112 GD, 187 GD, 227 GD, 70 GD, 115 GD e 164 GD, respectivamente, para a 'Cabernet Sauvignon', 'Tempranillo', 'Merlot', 'Tannat', 'Sauvignon Blanc', 'Chardonnay' e 'Gewurztraminer'.

Avaliando a cultivar 'Cabernet Sauvignon' no município de Uruguaiana, RS, BRIXNER et al. (2010) verificaram a necessidade térmica de $2208 \mathrm{GD}$ entre a brotação e a colheita, valor semelhante ao encontrado

Tabela 1 - Número de dias e graus dias necessários para as cultivares de Vitis vinifera, cultivadas na região da Campanha, completarem o ciclo (poda-colheita) nas safras 2007/2008, 2008/2009, 2009/2010, 2010/2011 e 2011/2012.

\begin{tabular}{|c|c|c|c|c|c|c|c|}
\hline Safra & CS & TT & SB & TP & MT & GT & $\mathrm{CH}$ \\
\hline \multicolumn{8}{|c|}{ - } \\
\hline $2007 / 2008$ & $175 \mathrm{bA}$ & $155 \mathrm{bC}$ & $143 \mathrm{cD}$ & $164 \mathrm{cB}$ & $155 \mathrm{cC}$ & $141 \mathrm{dE}$ & $156 \mathrm{aC}$ \\
\hline $2008 / 2009$ & $173 \mathrm{cA}$ & $148 \mathrm{cD}$ & $137 \mathrm{dF}$ & $159 \mathrm{~dB}$ & $145 \mathrm{dE}$ & $146 \mathrm{bE}$ & $154 \mathrm{bC}$ \\
\hline $2009 / 2010$ & $181 \mathrm{aA}$ & $159 \mathrm{aD}$ & $157 \mathrm{aE}$ & $169 \mathrm{aB}$ & $167 \mathrm{bC}$ & $149 \mathrm{aF}$ & $156 \mathrm{aE}$ \\
\hline $2010 / 2011$ & $173 \mathrm{cA}$ & $160 \mathrm{aC}$ & $149 \mathrm{bD}$ & $167 \mathrm{bB}$ & $167 \mathrm{bB}$ & $144 \mathrm{cE}$ & $148 \mathrm{cD}$ \\
\hline $2011 / 2012$ & $170 \mathrm{dA}$ & $156 \mathrm{bB}$ & $150 \mathrm{bC}$ & $170 \mathrm{aA}$ & $169 \mathrm{aA}$ & $145 \mathrm{bcE}$ & $147 \mathrm{cD}$ \\
\hline Média & 174 & 156 & 147 & 166 & 161 & 145 & 152 \\
\hline $2007 / 2008$ & $2066 \mathrm{cA}$ & $1831 \mathrm{bC}$ & $1721 \mathrm{cE}$ & as ------- & $1831 \mathrm{cC}$ & $1607 \mathrm{bF}$ & $1742 \mathrm{aD}$ \\
\hline $2008 / 2009$ & $2095 \mathrm{bA}$ & $1745 \mathrm{cD}$ & $1740 \mathrm{bD}$ & 1905 bB & $1801 \mathrm{dC}$ & $1690 \mathrm{aF}$ & $1709 \mathrm{bE}$ \\
\hline $2009 / 2010$ & $2055 \mathrm{cA}$ & $1670 \mathrm{dE}$ & 1755 bD & $1888 \mathrm{cB}$ & $1859 \mathrm{bC}$ & $1526 \mathrm{dG}$ & $1627 \mathrm{dF}$ \\
\hline $2010 / 2011$ & $2133 \mathrm{aA}$ & $1897 \mathrm{aC}$ & $1789 \mathrm{aD}$ & $1988 \mathrm{aB}$ & $1988 \mathrm{aB}$ & $1623 \mathrm{bF}$ & $1718 \mathrm{bE}$ \\
\hline $2011 / 2012$ & $2072 \mathrm{cA}$ & $1824 \mathrm{bC}$ & $1791 \mathrm{aD}$ & $2000 \mathrm{aB}$ & $1986 \mathrm{aB}$ & $1582 \mathrm{cF}$ & $1647 \mathrm{cE}$ \\
\hline Média & 2084 & 1793 & 1759 & 1937 & 1893 & 1606 & 1689 \\
\hline
\end{tabular}

Médias seguidas por mesmas letras minúsculas na coluna e maiúsculas na linha, não diferem entre si pelo teste de Tukey ( $\mathrm{p}=0,05$ ). CS (Cabernet Sauvignon), TT (Tannat), SB (Sauvignon Blanc), TP (Tempranillo), MT (Merlot), GT (Gewürztraminer) e CH (Chardonnay).

Ciência Rural, v.45, n.4, abr, 2015. 


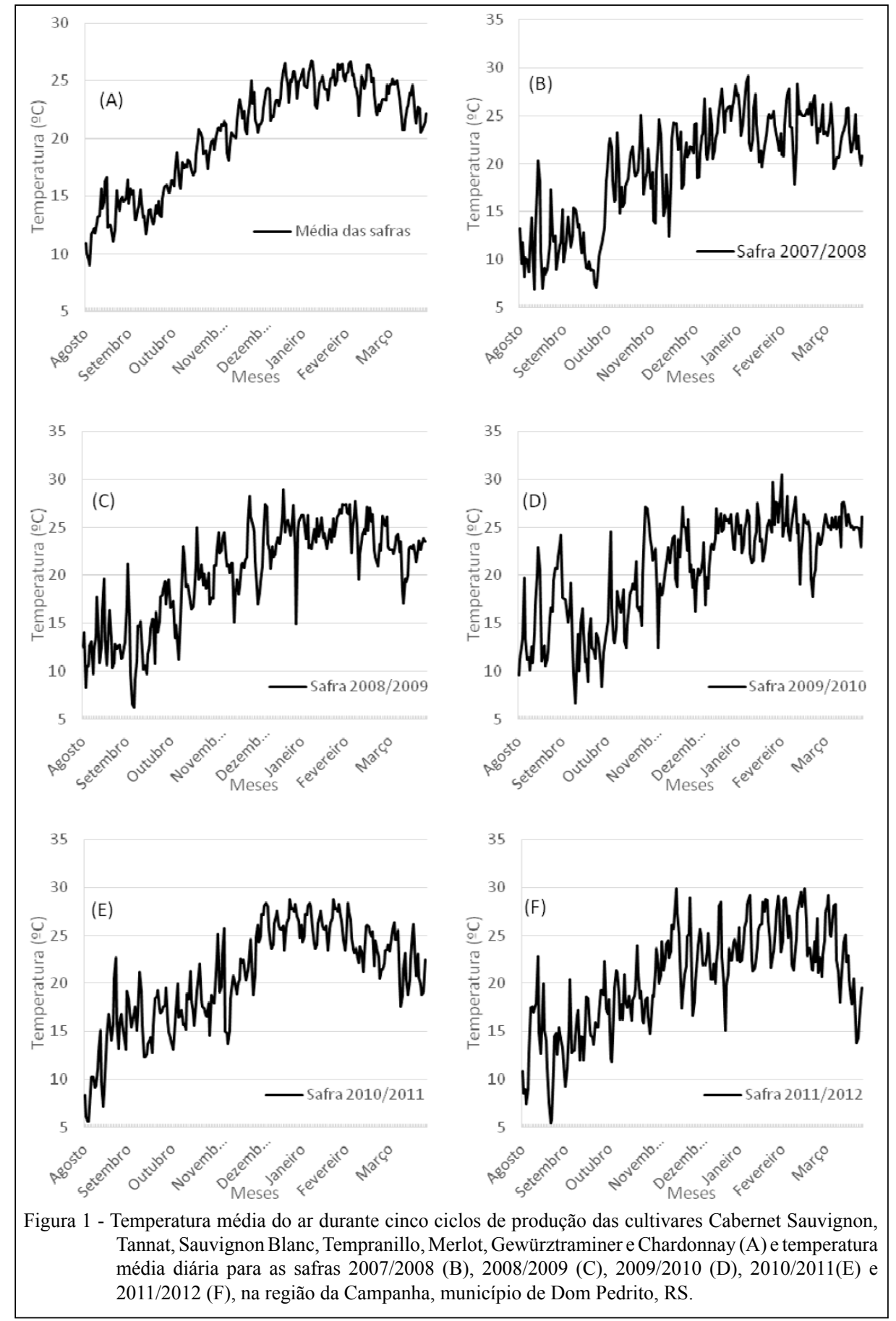

na presente pesquisa. Pesquisando as necessidades térmicas e o número de dias para completar o ciclo de cultivares europeias de videira no município de Santana do Livramento, RS, durante 18 safras, COSTA (2011) verificou que a cultivar 'Cabernet Sauvignon' variou entre 1444 a 2341 GD e 150 a 184 dias, a 'Chardonnay' entre 1449 a 1853 GD e 140 a 177, 'Sauvignon Blanc' entre 1396 a 1832 GD e 114 a 151, 'Merlot' entre 1514 a
2221 GD e 151 a 200 dias, valores estes que contemplam os obtidos no presente trabalho.

No município de São Joaquim, SC, BRIGHENTI et al. (2013) verificaram que, entre brotação e colheita, foram necessários 1194 GD e 175 dias para 'Sauvignon Blanc', 1296 GD e 208 dias para 'Chardonnay', 1402 GD e 212 dias para 'Merlot', 1430 GD e 214 dias para 'Cabernet Sauvignon'. Ao 
comparar os resultados obtidos por BRIGHENTI et al. (2013) com as necessidades térmicas (Tabela 1) e com o número de dias para completar o ciclo (Tabela 1), obtidos na região da Campanha, constata-se o efeito da altitude elevada na duração do ciclo da videira, isto porque, em São Joaquim, houve necessidade em dias superior à encontrada no presente trabalho, entretanto, com acúmulo térmico inferior ao encontrado na região da Campanha, para todas as cultivares pesquisadas. Isso corrobora os resultados obtidos por KISHINO \& MARUR (2007), os quais atribuem as diferenças encontradas entre regiões, principalmente, à temperatura do ar distinta entre os locais de cultivo.

Da mesma maneira que em São Joaquim, valores menores aos verificados no presente trabalho são encontrados para o Paraná, onde SANTOS et al. (2007) verificaram a necessidade térmica de 1296 GD para a 'Cabernet Sauvignon' e 1376 GD para a 'Tannat'. Ainda no Paraná, RUFFO ROBERTO et al. (2005) constataram a necessidade de 126 dias e de 1221 graus-dia para a 'Cabernet Sauvignon'. $\mathrm{Na}$ região da Serra Gaúcha, SATO et al. (2011) encontraram, para as cultivares 'Cabernet Sauvignon' e 'Tannat', respectivamente, a necessidade de 130 e 131 dias para completar o ciclo.

Ao converter as diferenças médias em graus-dia, entre as safras, para dias, através da divisão pela temperatura média dos ciclos, de $21,6^{\circ} \mathrm{C}$ (Figura 1A), verifica-se diferença em dias de 3,6, $5,2,8,7,10,5,3,2,5,3$ e 7,6, respectivamente, para a 'Cabernet Sauvignon', 'Tempranillo', 'Merlot', 'Tannat', 'Sauvignon Blanc', 'Chardonnay' e 'Gewurztraminer'. Quando comparada esta diferença à diferença observada, em dias, (11 para 'Cabernet Sauvignon', 11 'Tempranillo', 24 'Merlot', 12 'Tannat', 20 'Sauvignon Blanc', 10 'Chardonnay' e 8 'Gewurztraminer'), constata-se que a demanda térmica, em graus-dia, é melhor preditor para estimar o ciclo das videiras na região da Campanha do que o número de dias para completar o ciclo.

A necessidade térmica (graus-dia) e a necessidadeem diasparacompletaras fases fenológicas de Desenvolvimento das Folhas, Aparecimento das Inflorescências, Floração, Desenvolvimento do Fruto e Maturação são apresentados para as safras 2010/2011 e 2011/2012, nas figuras 2 e 3 . Em

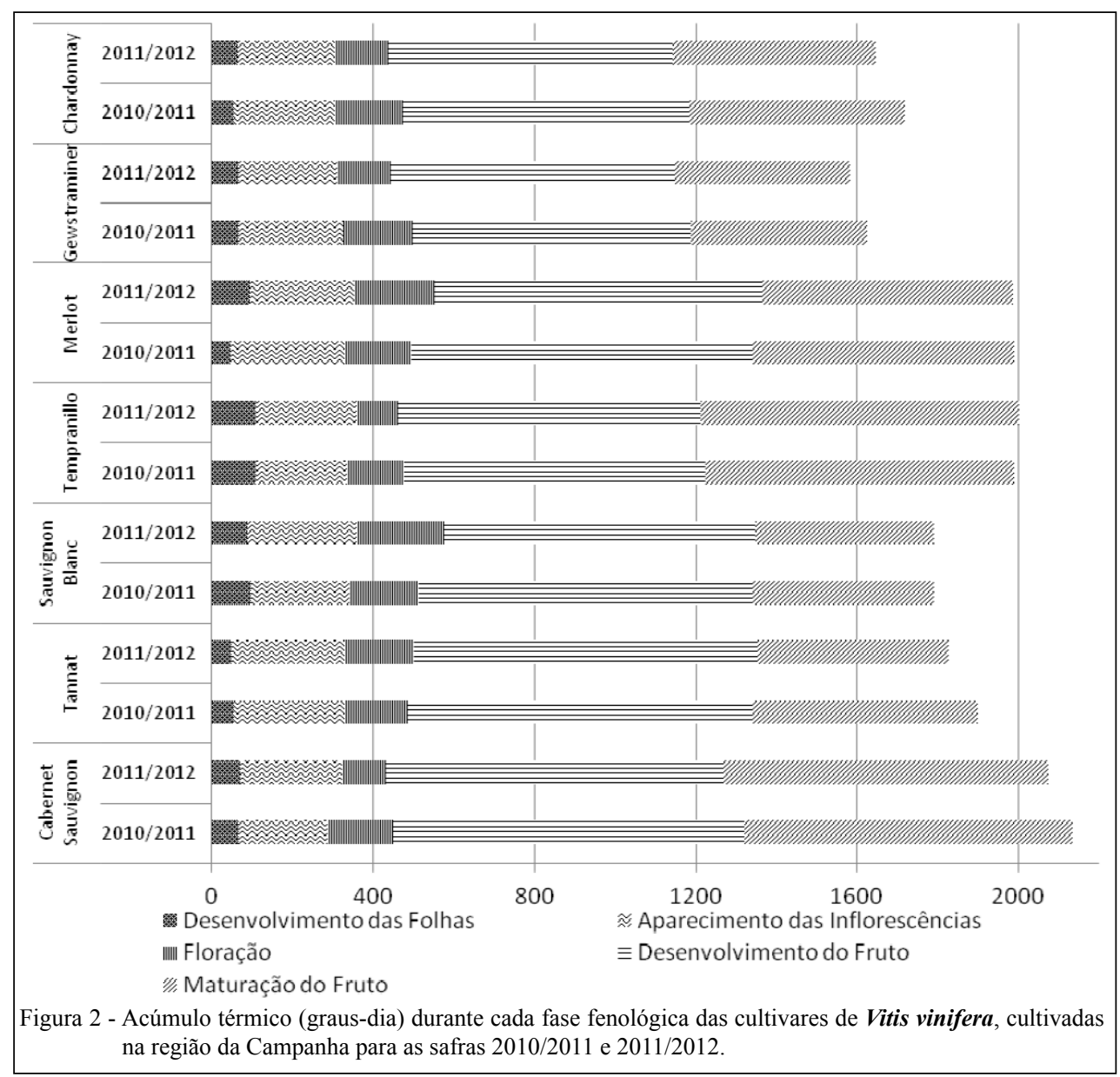

Ciência Rural, v.45, n.4, abr, 2015. 


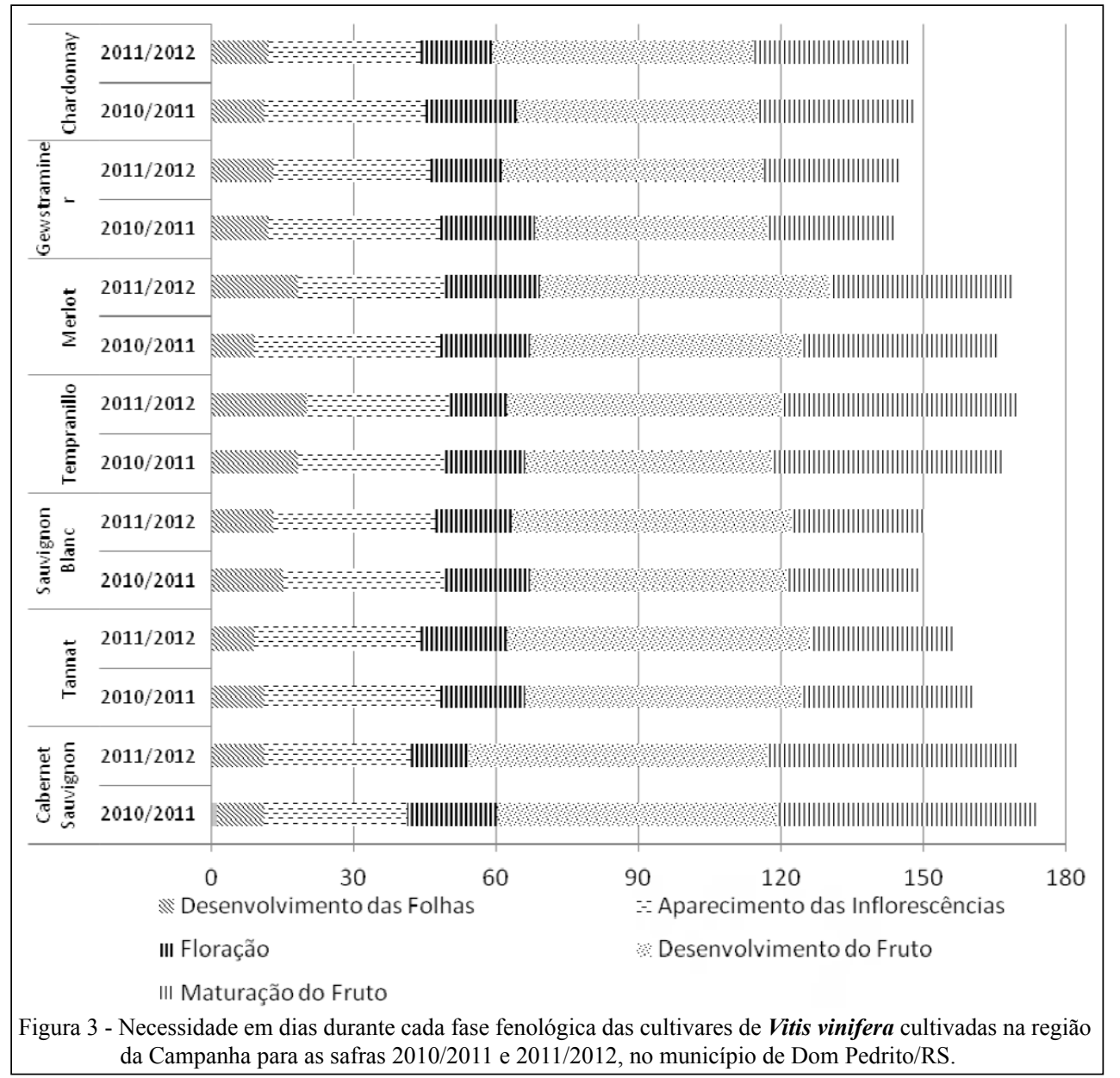

geral, a fase com maior necessidade térmica (GD) é a de desenvolvimento do fruto, necessitando, em média, 854 GD para 'Cabernet Sauvignon', 749 para 'Tempranillo', 830 para a 'Merlot', 854 para 'Tannat', 798 para a 'Sauvignon Blanc', 707 para a 'Chardonnay' e 697 para a 'Gewurztraminer'.

Trabalhos realizados em São Joaquim, SC, como o de BRIGHENTI et al. (2013), demonstram, sob diferentes cultivares, duração média para a fase de maturação, de 289 GD para 'Sauvignon Blanc', 467GD para 'Chardonnay', 541 GD para 'Merlot', 522 GD para 'Cabernet Sauvignon'. Estes resultados são inferiores aos encontrados no presente trabalho, para a região da Campanha, onde, em média, é necessário 446, 520, 634 e 809 GD, respectivamente, para as cultivares 'Sauvignon Blanc', 'Chardonnay', 'Merlot' e 'Cabernet Sauvignon'. Tal fato deve-se, provavelmente, às maiores temperaturas encontradas na região da Campanha, para a fase de maturação do fruto. Isto porque, em média, as uvas cultivadas em São Joaquim, SC, ficaram no vinhedo durante a fase de maturação, 19 dias a mais que na região da
Campanha, o que equivale a $32 \%$ maior necessidade em dias em São Joaquim, SC.

\section{CONCLUSÃO}

Ocomportamento fenológico foi influenciado pela cultivar em estudo, mas também pela safra avaliada. Tendo sido verificada a maior necessidade térmica na fase de desenvolvimento e maturação do fruto e a menor necessidade para a fase de floração.

Valores em graus-dia são melhores preditores do ciclo, quando comparados aos dados em dias. Constatou-se necessidades térmicas médias para completar o ciclo de: 2084 GD para a 'Cabernet Sauvignon', 1937 GD para 'Tempranillo', 1893 GD para a 'Merlot', 1793 GD para 'Tannat', 1759 GD para a 'Sauvignon Blanc', 1689 GD para a 'Chardonnay' e 1606 GD para a 'Gewurztraminer'.

\section{AGRADECIMENTOS}

À estância Guatambu, pela possibilidade de execução da pesquisa. Aos programas de Pós-graduação em Sistemas 
de Produção Agrícola Familiar (PPG SPAF) e Pós-graduação em Agronomia (PPGA - UFPel). Ao Conselho Nacional de Desenvolvimento Científico e Tecnológico $(\mathrm{CNPq})$, pela concessão da bolsa de Doutorado.

\section{REFERÊNCIAS}

BRIGHENTI, A.F. et al. Caracterização fenológica e exigência térmica de diferentes variedades de uvas viníferas em São Joaquim, Santa Catarina - Brasil. Ciência Rural, v.43, p.1162-1167, 2013. Disponível em: <http://www.scielo.br/scielo.php?pid=S010384782013005000082\&script $=$ sci_arttext $>$. Acesso em: 12 nov. 2013. doi: 10.1590/S0103-84782013005000082.

BRIXNER, G.F. et al.Caracterização fenológica e exigência térmica de videira Vitis vinífera cultivadas no município de Uruguaiana na região da fronteira oeste - RS. Revista da Faculdade de Zootecnia Veterinária e Agronomia, v.17, p.249-261, 2010. Disponível em: <http://revistaseletronicas.pucrs.br/ojs/index.php/ fzva/article/view/7308>. Acesso em: 14 nov. 2013.

BORGHEZAN, M. et al. Comportamento vegetativo e produtivo da videira e composição da uva em São Joaquim, Santa Catarina. Pesquisa Agropecuária Brasileira, v.46, p.398-405, 2011. Disponível em: <http://ainfo.cnptia.embrapa.br/digital/bitstream/ item/50738/1/46n04a09.pdf>. Acesso em: 04 set. 2013.

COSTA, V.B. Efeito das condições climáticas na fenologia da videira européia em Santana do Livramento, Rio Grande do Sul. 2011. 89f. Tese (Doutorado em Agronomia) - Programa de Pósgraduação em Agronomia, Universidade Federal de Pelotas, RS.

FERREIRA, E.A. et al. Antecipação de safra para videira Niágara Rosada na região sul do Estado de Minas Gerais. Ciência e Agrotecnologia (UFLA), v.28, p.1221-1227, 2004. Disponível em: <http://www.cloud.editora.ufla.br/revistas/cienagro/pdf/28-62004_01.pdf>. Acesso em: 12 nov.2013.

KISHINO, A.Y.; MARUR, I.P.H. Fatores climáticos e o desenvolvimento da videira. In: KISHINO, A.Y. Viticultura Tropical. Londrina, IAPAR, 2007. p.59-86.

LEÃO, P.C.S.; SILVA, E.E.G. Caracterização fenológica e requerimentos térmicos de variedades de uvas sem sementes no vale do São Francisco. Revista Brasileira de Fruticultura, v.25, p.379-382, 2003. Disponível em: <http://www.scielo.br/pdf/rbf/ v25n3/18647.pdf>. Acesso em: 09 maio 2014.

MONTEIRO, J.E.B.A. (Org.). Agrometeorologia dos cultivos: o fator meteorológico na produção agrícola. Brasília, DF: Instituto Nacional de Meteorologia, 2009. 530p.
MORLAT, R.; BODIN, F. Characterization of viticulture terroirs using a simple field model based on soil depth - II. Validation of the grape yield and berry quality in the Anjou vineyard. Plant and Soil. v.281, p.55-69, 2006. Disponível em: <http://link.springer. com/article/10.1007\%2Fs11104-005-3769-z?LI=true>. Acesso em: 15 out. 2013.

NEIS, S. et al. Caracterização fenológica e requerimento térmico para a videira Niágara Rosada em diferentes épocas de poda no sudoeste goiano. Revista Brasileira de Fruticultura, v.32, p.931-937, 2010. Disponível em: <http://www.scielo. br/scielo.php?pid=S0100-29452010000300038\&script $=$ sci abstract\&tlng=pt $>$. Acesso em: 07 mar. 2013

RADÜNZ, A.L. et al. Efeitos da época da poda sobre a duração do ciclo e a produção de videiras 'Bordô' e 'BRS Violeta'. Científica Rural (URCAMP), v.14, p.213-224, 2012.

RUFFO ROBERTO, S. et al. Caracterização da fenologia e exigência térmica (graus-dias) para a uva 'Cabernet Sauvignon' em zona subtropical. Acta Scientiarum Agronomy. v.27, p.183187, 2005. Disponível em: <http://redalyc.uaemex.mx/src/inicio/ ArtPdfRed.jsp?iCve=187117080024> . Acesso em: 07 nov. 2013.

SANTOS, C.E. et al. Caracterização da fenologia e da demanda térmica das videiras 'Cabernet Sauvignon' e 'Tannat' para a região norte do Paraná. Acta Scientiarum Agronomy. v.29, p.361-366, 2007. Disponível em: <http://periodicos.uem.br/ojs/index.php/ ActaSciAgron/article/view/288>. Acesso em: 03 dez. 2012

SATO, A.J. et al. Fenologia, produção e composição do mosto da 'Cabernet sauvignon' e 'Tannat' em clima subtropical. Revista Brasileira de Fruticultura, v.33, p.491-499,2011. Disponível em: $<$ http://www.scielo.br/pdf/rbf/v33n2/aop06011.pdf $>$. Acesso em: 12 ago. 2013.

SILVA, R.J.L. et al. Efeito da poda antecipada e regime de irrigação nos teores de açúcares em uvas Niágara Rosada. Ciência e Agrotecnologia (UFLA), v.33, p.844-847, 2009. Disponível em: <http://www.scielo.br/scielo.php?script=sci_artte xt\&pid=S1413-70542009000300025>. Acesso em: 05 nov. 2013.

VAN LEEUWEN, C. et al. Influence of climate, soil, and cultivar on terroir. American Journal of Enology and Viticulture. v.55, p.207-217, 2004. Disponível em: <http://www-ecole.enitab.fr/ people/kees.vanleeuwen/articles/PI-17\%20Influence\%20of $\% 20$ climate $\% 20$ soil $\% 20$ and $\% 20$ cultivar\%20on\%20terroir.pdf>. Acesso em: 10 dez. 2013.

WEBB, L.B. et al. Modelled impact of future climate change on the phenology of winegrapes in Australia. Australian Journal of Grape and Wine Research. v.13, p.165-175, 2007. Disponível em: $<$ http:// wineserver.ucdavis.edu/pdf/attachment/1109.\%20Australian $\% 20$ climate\%20change\%20model.pdf>. Acesso em: 09 mar. 2013. 